\title{
KERAGAMAN VEGETASI GULMA DI BAWAH TEGAKAN POHON \\ KARET ( Hevea brasiliensis ) PADA UMUR DAN ARAH LERENG YANG \\ BERBEDA DI PTPN IX BANYUMAS
}

\author{
Bhaskara Anggarda Gathot Subrata ${ }^{1}$, Bayu Aji Setiawan ${ }^{2}$ \\ 1) Program Studi Agroteknologi STIPER Petra Baliem Wamena, \\ 2) Alumni Fakultas Pertanian Universitas Jenderal Soedirman
}

\begin{abstract}
This research was conducted in PTPN IX Afdeling Krumput Banyumas in July 2016, with observational survey method is by field orientation, exploration, and analysis of vegetation. The data collection is done by means of interviews and direct observation. Preliminary surveys conducted to seek information from relevant agencies, environmental conditions around the rubber planting. The main survey is done to take samples of weeds in every age group, every group performed 5 times the sampling is considered to represent the age group. The variables measured were type of weed, SDR, and the coefficient Communities $(C)$.The results showed that the weed dominant in the younger age group (1-5 years): Cyperus Kyllingia, Axonopus compressus, Clibadium Surinames, adolescent age group (6-10 years): Cyperus Kyllingia, Paspalum conjugatum Berg, Calopogonium mucuinoides Desv., Group age youth (11-15 years): Cyperus Kyllingia, Paspalum conjugatum Berg, Chromolaena odorata., adult group (16-20 years): Eleusine indica, Paspalum conjugatum Berg, Chromolaena odorata, then the dominant weeds on the slopes of the West-East direction (BT ) is Calopogonium mucuinoides Desv., Clibadium Surinames, Paspalum conjugatum Berg, and the dominant weed species in the North-South direction of the slope (US) is Calopogonium mucuinoides Desv., Paspalum conjugatum Berg., and Axonopus compressus. Weeds dominant age group and Directions Slope is Cyperus killingia and Eleusine indica $(L)$, Paspalum conjugatum Berg, Axonopus compressus, Clibadium Surinames and Calopogonium mucuinoides Desv.
\end{abstract}

Keywords : weeds, rubber tree, group age, slopes, SDR

\section{PENDAHULUAN}

Tanaman Karet (Hevea brasiliensis) merupakan tanaman perkebunan yang penting, baik dalam konteks ekonomi masyarakat maupun sumber penghasil devisa non migas bagi negara. Tanaman karet berasal dari daerah tropika lembah Amazon Brazilia dengan curah hujan 2000-3000 mm/tahun dan hari hujan antara 120-170 hari/tahun (Sutardi, 1981).

Salah satu permasalahan pada tanaman karet adalah gulma yang sangat mempengaruhi hasil lateks. Walaupun tanaman karet tumbuh rapat, tetapi tetap ada gulma yang di sekitar tanaman karet dan untuk mengatasinya perlu diketahui jenis gulma yang mengganggu pertumbuhan tanaman karet, sehingga dapat ditentukan cara mengatasinya. Jenis gulma akan berbeda pada setiap umur tanaman karet, hal ini tergantung pada lokasi, iklim setempat, dan cahaya yang diterima (Sastroutomo, 1990 dalam Rosanti, 2011). Selain itu, perbedaan umur tanaman juga menyebabkan terjadinya pergeseran dominasi gulma. Pada tanaman dengan persentase penutupan tajuk rendah akan ditemukan jenis gulma beragam dan 
sebaliknya pada tanaman dengan persentase penutupan tajuk lebih besar lebih didominasi gulma yang tahan naungan (Budiarto, 2001).

Jenis-jenis gulma penting pada perkebunan karet diantaranya yaitu jenis gulma golongan rumput (Imperata cylindrica, Paspalum conjugatum, Otto chloanodosa, dan Polygala paniculat), jenis daun lebar (Mikania cordata, M. micrantha, Melastomama labatrichum, Clibadium surinamensis) dan jenis rumput 4 teki Cyperus kyllingia, C.rotundus dan Scleria sumatrensis) (Tjitrosoedirdjo et al., 1984). Akan tetapi informasi jenis gulma tersebut tidak didasarkan pada perbedaan umur tanaman karet (Mangoensoekardjo, 1982).

Arah baris dan kerapatan populasi tanaman mempengaruhi besarnya transmisi cahaya yang diterima tanaman di bawah tegakan. Ketika arah baris searah dengan datangnya sinar matahari dengan jarak tanam lebar, akan terdapat efek lorong yang mengakibatkan adanya energi radiasi yang tidak digunakan tanaman. Akan tetapi justru akan mendorong pertumbuhan gulma, karena cukup memeperoleh cahaya matahari. Oleh karena itu, perlu adanya pengaturan jarak tanam dan arah baris yang tepat agar penerimaan energi radiasi oleh tanaman lebih efisien.

Adapun tujuan dilakukan penelitian ini adalah : 1) Untuk mengetahui keragaman vegetasi gulma yang tumbuh dan dominasi di bawah tegakan pohon karet pada kelompok umur tanaman muda (1-5 Tahun), remaja (6-10 tahun), taruna (11-15 tahun), dewasa (16-20 tahun). 2) Untuk mengetahui keragaman vegetasi gulma dan dominasi pada perbedaan arah lereng Utara-Selatan (US) dan Timur-Barat (TB) pada lahan pertanaman karet. 3) Untuk mengetahui keragaman vegetasi gulma dan dominasi pada umur dan arah lereng yang berbeda pada lahan pertanaman karet.

\section{BAHAN DAN METODE}

Penelitian telah dilaksanakan di Perkebunan Tanaman Karet Afdeling Krumput PTPN IX Banyumas. Penelitian dilaksanakan Juli 2016. Jenis tanah pada Afdeling Krumput adalah Ultisol. Ketinggian tempat berkisar 175 - 250 mdpl.

Bahan yang digunakan dalam kegiatan penelitian ini adalah Pertanaman Karet dengan umur berbeda: tanaman muda (U1: 1-5 Tahun), remaja (U2: 6-10 tahun), taruna (U3: 11-15 tahun), dewasa (U4: 16-20 tahun). Alat yang digunakan dalam kegiatan penelitian ini adalah cangkul, petak kuadrat ukuran $0.5 \mathrm{~m} \mathrm{x}$ 0.5m, amplop kertas, kantong plastik, oven, buku taksonomi gulma, lux meter, timbangan analitik dan kamera.

Penilitian ini menggunakan metode survey observatif yaitu dengan orientasi 
lapang, penjelajahan, dan analisis vegetasi.

Gulma yang diamati pada areal berdasarkan kelompok umur tanaman karet muda (U1: 1-5 Tahun), remaja (U2: 6-10 tahun), taruna ( U3: 11-15 tahun), dewasa (U4: 16-20 tahun) dan juga arah lereng Utara-Selatan (US), Timur-Barat (TB) yang cenderung berbukit dengan kemiringan $5^{\circ}-40^{\circ}$. Pengambilan sampel dilakukan pada setiap areal pertanaman karet berdasarkan kelompok umur berbeda dengan metode kuadrat dan juga mengamati keragaman gulma pada arah lereng pada setiap kelompok umur pertanaman karet. Distribusi petak sampel pada setiap areal dilakukan sebanyak 5 kali pada setiap kelompok dan dianggap sudah mewakili vegetasi pada setiap kelompok areal pengamatan.

Variabel pengamatan yang diamati adalah jenis gulma, kerapatan mutlak gulma, kerapatan nisbi, frekuensi mutlak gulma, frekuensi nisbi gulma, dominansi mutlak gulma, dominansi nisbi.

Analisis data vegetasi gulma dilakukan dengan cara menghitung nilai SDR dari setiap areal yang diamati berdasarkan umur kelompok tanaman karet. Untuk menghitung Summed Dominance Ratio (SDR). Rumus yang digunakan sebagai berikut:

$\operatorname{SDR}(\%)=\frac{K N+F N+D N}{3}$
$\mathrm{KN}=$ Kerapatan Nisbi $=$

$\frac{\text { kerapatan mutlak suatu jenis }}{\text { Jumlah kerapatan mutlak suatu jenis }} \times 100 \%$

$\mathrm{FN}=$ Frekuensi Nisbi $=$

$\frac{\text { Frekwensi mutlak suatu jenis }}{\text { Jumlah frekuensi mutlak swatu jenis }} \times 100 \%$

$\mathrm{DN}=$ Dominansi Nisbi $=$

$\frac{\text { Dominansi mutlak suatu jenis }}{\text { Jumlah dominansi mutlak suatu jenis }} \times 100 \%$

Selanjutnya Atas dasar SDR tiap jenis gulma, maka untuk membandingkan dua komunitas gulma dapat Koefesien Komunitas Gulma (C). Rumus yang digunakan sebagai berikut:

$\mathrm{C}=\frac{2 w}{a+b} \times 100 \%$

Keterangan:

$\mathrm{C}=$ Koefesien komunitas

$\mathrm{W}=$ Jumlah total dua kuantitas terendah untuk jenis dari masing-masing komunitas

$\mathrm{a}=$ jumlah total dari seluruh kuantitas pada komunitas pertama

$\mathrm{b}=$ jumlah total dari seluruh kuantitas pada komunitas ke dua

Bila nilai C Lebih besar atau sama dengan $75 \%$ berarti komunitas gulma tidak beda nyata atau komunitas gulmanya seragam. Sebaliknya jika nilai C kurang dari $75 \%$ berarti gulmanya tidak seragam.

\section{HASIL DAN PEMBAHASAN}

Keadaan Fisik PTPN IX Banyumas

Penelitian ini dilakukan di PT. Perkebunan Nusantara IX terletak di Kabupaten Banyumas dan secara geografis terletak pada posisi 70-35' - 70-40' 
Lintang Selatan dan 1080 - 35' - 109005' Meridian Timur. Lokasi penelitian di PT. Perkebunan Nusantara IX Banyumas dilakukan di Afdeling Krumput.

Menurut sistem iklim klasifikasi Oldeman (1975) yang menggunakan kriteria bulan basah (curah hujan > 200 $\mathrm{mm}$ ) dan bulan kering (curah hujan $<100$ mm) berturut-turut, maka di PTPN IX memiliki iklim tipe $\mathrm{B}$ yang dicirikan dengan panjang periode bulan basah 3-4 bulan berturut-turut, sedangkan menurut Koppen termasuk tipe iklim Af. Menurut Schmidth dan Ferguson (1951) di PTPN IX termasuk dalam tipe iklim B yang

Tabel 1. Data rerata curah hujan Kebun Krumput PTPN IX Banyumas Th. 2015 dan Th. 2016

\begin{tabular}{lcccc}
\hline \multirow{2}{*}{ Bulan } & \multicolumn{2}{c}{2015} & \multicolumn{2}{c}{2016} \\
\cline { 2 - 5 } & Jumlah mm & Jumlah hari & Jumlah mm & Jumlah hari \\
\hline Januari & 307 & 7 & 309 & 15 \\
Februari & 82 & 4 & 363 & 10 \\
Maret & 385 & 11 & 298 & 9 \\
April & 67 & 4 & 183 & 7 \\
Mei & 34 & 1 & 206 & 4 \\
Juni & 0 & 0 & 391 & 9 \\
Juli & 0 & 0 & 219 & 9 \\
Agustus & 0 & 0 & - & - \\
September & 0 & 0 & - & - \\
Oktober & 0 & 0 & - & - \\
November & 317 & 9 & - & - \\
Desember & 366 & 12 & - & \\
\hline
\end{tabular}

Sumber : Data primer diolah, 2016

Tabel 2. Rerata Suhu $\left({ }^{0} \mathrm{C}\right)$, Kelembaban $(\%)$ dan Intensitas Cahaya(lux) arah lereng Barat-Timur

\begin{tabular}{cccccccccc}
\hline Kelompok & \multicolumn{3}{c}{ Suhu } & \multicolumn{4}{c}{ Kelembaban $(\%)$} & \multicolumn{3}{c}{ Intensitas Cahaya (lux) } \\
\cline { 2 - 10 } Umur & Pagi & Siang & Sore & Pagi & Siang & Sore & Pagi & Siang & Sore \\
\hline U1 & 26 & 30 & 29 & 56 & 47 & 40 & 989 & 1932 & 1321 \\
U2 & 27 & 32 & 32 & 55 & 46 & 41 & 1875 & 8943 & 2863 \\
U3 & 26 & 32 & 31 & 50 & 45 & 38 & 2136 & 10281 & 3127 \\
U4 & 29 & 32 & 32 & 50 & 37 & 35 & 2983 & 19450 & 3658 \\
\hline
\end{tabular}

Sumber : Data primer diolah, 2016 
Jenis tanah yang terdapat di PTPN IX Banyumas adalah jenis tanah latosol yang mempunyai $\mathrm{pH}$ yang agak masam. Kadar air, bahan organik dan $\mathrm{K}$ tersedia dalam kondisi sedang. Jika dilihat dari kandungan $\mathrm{N}$ total dan $\mathrm{P}$ tersedia nilainya sangat rendah. Selain itu nilai $\mathrm{C} / \mathrm{N}$ dan KPK nya juga rendah. Satu-satunya nilai yang tinggi hanya ditunjukkan oleh $\mathrm{K}$ tersedia (Tabel
Berdasarkan pengamatan jenis tanah yang terdapat di lokasi penelitian adalah jenis tanah Latosol dengan warna kemerahan yang cukup terang, memiliki struktur lempung dan tidak mudah berubah bentuk karena tekanan dan dalam keadaan basah mudah dibentuk, bila lembab bersifat teguh dan bila kering tanah Latosol menjadi keras.

$3)$.

Tabel 3. Hasil analisis sifat kimia tanah Latosol di PTPN IX Banyumas

\begin{tabular}{clrc}
\hline No & Sifat kimia tanah Latosol & Nilai & Keterangan \\
\hline 1 & pH & 5,88 & Agak masam \\
2 & Kadar air gravimetric $(\mathrm{Ag})$ & 7,20 & Sedang \\
3 & BO $(\%)$ & 2,60 & Sedang \\
4 & C $(\%)$ & 1,51 & Sedang \\
5 & N Total $(\mathrm{N})$ & 0,08 & Sangat rendah \\
6 & C/N & 18,87 & Rendah \\
7 & P-Tersedia & 17,80 & Sangat rendah - sedang \\
8 & K-Tersedia & 0,63 & Tinggi \\
9 & KPK & 14,40 & Rendah \\
\hline
\end{tabular}

Sumber : Arsip data PTPN IX Banyumas Kebun Krumput, 2016

\section{Keragaman Vegetasi}

Pada kelompok umur tanaman muda 1-5 tahun (Tabel 4) terdiri dari 11 jenis vegetasi. Jenis vegetasi gulma yang tumbuh pada kelompok umur 1-5 tahun di dominasi oleh Clibadium surinamense pada arah lereng Barat-Timur dengan nilai SDR $20,55 \%$ dan pada arah lereng UtaraSelatan gulma yang tumbuh dominan ialah Axonopus Compressus.

\section{Clibadium Surinames sangat} merugikan tanaman karet karena efek persaingan yang berat, bila tumbuh di perkebunan tertentu baik pada areal TBM maupun TM, gulma ini perlu diberantas.
Selain itu, pada kelompok umur ini tajuk tanaman karet belum terbuka, sehingga cahaya yang diterima sangat tinggi karena Clibadium Surinames merupakan kelompok gulma berdaun lebar yang dominan pada perkebunan karet atau disebut juga dengan kelompok gulma yang butuh banyak cahaya (gulma tidak tahan naungan).

Sedangkan menurut Wiroatmojo (1993) gulma ini memiliki daya adaptasi yang tinggi dan merupakan salah satu jenis gulma berdaun lebar yang mengganggu pertumbuhan dan hasil tanaman budidaya. Gulma ini banyak hidup dan sering 
menginfestasi ladang, kebun seperti teh, karet, tebu dan lain-lain.

Dari hasil di atas dapat dilihat bahwa tumbuhan yang mendominasi pada kelompok umur U1 (1-5 tahun) dan arah lereng yang berbeda. Hal ini menggambarkan bahwa kondisi fisik menyebabkan gulma yang mampu tumbuh di kedua lokasi penelitian ini pun berbeda. Kondisi fisik (Tabel 2) pada lokasi suhunya sangat panas $\left(30^{\circ} \mathrm{C}\right)$ dan intensitas cahayanya juga relatif tinggi (2003 lux). Intensitas cahaya memberikan pengaruh pada perkembangan dan pertumbuhan jenis vegetasi. Pada kelompok umur 1-5 tahun selain Clibadium Surinames, ada Axonopus Compressus yang mendominasi arah lereng utara-selatan dengan SDR 17,44\%.

A. compressus disebut juga gulma daratan, jenis gulma dataran yang tumbuh di perkebunan sangat tergantung pada jenis tanaman budidaya, jenis tanah, iklim dan pola tanam. Dimana derajat persaingan antara gulma dan tanaman tergantung pada densitas jenis gulma, varietas tanaman dan tingkat pemupukan (Hasanuddin et.al., 2012).

Jumlah SDR jenis vegetasi pada kelompok umur tanaman remaja 6-10 tahun, diperoleh 13 jenis vegetasi yang tumbuh dibawah tegakan tanaman karet. Gulma yang mendominasi pada semua arah lereng dengan nilai SDR 22,01\% dan 20,57\%, ialah Mucuna bracteata. Menurut pemaparan dari mandor pemeliharaan dan penanganan gulma, Mucuna bracteata digunakan sebagai tanaman penutup tanah karena sifatnya sifatnya yang dapat mengikat nitrogen dan mencegah erosi, memperbaiki sifat fisik dan struktur tanah, meningkatkan kandungan bahan organik dan hara tanah serta, menekan pertumbuhan gulma. Penanaman LCC dapat mengurangi kehilangan nitrogen dalam tanah, sebagai contoh penanaman LCC disekitar tanaman pokok dapat menekan tingkat populasi gulma yang ada. Hal ini untuk mengantisipasi adanya erosi karena melihat jenis tanah pada lokasi umur tanaman 1-5 tahun ini adalah tanah Latosol yang mudah terbawa erosi.

Vegetasi ini sengaja ditanam di beberapa lokasi kebun yang mendapat cukup penyinaran matahari sehingga pertumbuhannya tidak terganggu dan dapat memberikan manfaat yang optimal pada tanaman karet. Mucuna bracteata. Bisa ditemukan di pinggir jalan dan di daerah kebun yang tidak terlalu dalam.

Pada daerah yang terletak di pinggir akan mendapat sinar matahari yang lebih banyak dibandingkan dengan bagian tengah kebun, sehingga pertumbuhan tanaman penutup kacangan lebih baik pertumbuhannya. Penanaman Mucuna bracteata. Juga dapat menekan laju pertumbuhan gulma tekian, pada Tabel 5. nilai SDR gulma rerumputan menunjukkan 
nilai terendah dibandingkan dengan jenis gulma lainnya.

Gulma daun lebar jenis Clibadium Surinamense dengan nilai SDR 11,89\% cukup mendominasi diantara vegetasi lainnya setelah Mucuna bracteata. Gulma ini termasuk kedalam gulma yang merugikan dan perlu adanya pengendalian atau pemberantasan. Gulma Clibadium Surinames. sangat berbahaya pada kondisi lahan kering dan kebun memasuki fase gugur daun di musim kemarau. Gulma ini sangat mudah terbakar dan memicu kebakaran di kebun karet. Selain itu, apabila dibiarkan tumbuh Clibadium Surinames akan tumbuh mencapai tinggi 12 meter sehingga akan menyulitkan proses eksploitasi dan manajemen tanaman.

Diketahui bahwa di bawah tegakan tanaman karet dengan kelompok umur 1115 tahun (Tabel 6) diperoleh 10 jenis vegetasi. Jenis vegetasi yang mendominasi kelompok umur 11-15 tahun adalah Calopogonium mucuinoides Desv dengan nilai SDR 23,26\% dan 16,13\%.

Calopogonium mucunoides Desv dapat tumbuh baik pada tanah dengan tekstur ringan sampai berat, gulma ini tidak tahan terhadap genangan air yang tinggi. Calopogonium mucunoides Desv dapat tumbuh cepat pada semua tekstur tanah, walaupun dengan $\mathrm{pH}$ rendah $\left(\mathrm{H}_{2} \mathrm{O}\right)$ antara 4,5-5.
Pada kelompok umur ini arah lereng barat-timur maupun utara-selatan mempunyai naungan yang lumayan dapat membuat Calopogonium mucunoides Desv tumbuh mendominasi di arah lereng barattimur dan utara-selatan dengan intensitas cahaya paling tinggi 13732 lux pada utaraselatan kemudian 10281 lux pada barattimur, karena kanopi pada kelompok umur ini juga sudah terbuka akan sangat dapat membantu gulma ini tumbuh dominan. Gulma ini tumbuh menjalar dan membelit tanaman yang tumbuh di dekatnya. Ruas tanaman yang menempel pada tanah dapat mengeluarkan akar serabut. Pada akar serabut terserbut, banyak dijumpai bintil akar yang mengandung bakteri Rhizobium. (Purwanto, 2011)

\section{Calopogonium mucunoides Desv juga} dikenal sebagai LCC di perkebunan karet, dikenal sebagai satu jenis kacang polong pelopor untuk melindungi permukaan lahan, mengurangi temperatur lahan, memperbaiki kandungan nitrogen, meningkatkan kesuburan lahan dan mengendalikan pertumbuhan rumput liar.

Jenis vegetasi yang terdapat dibawah tegakan karet umur 16-20 tahun berjumlah 16 jenis. Jenis vegetasi gulma yang mendominasi adalah Paspalum conjugatum Berg dengan nilai SDR sebesar 24,54\% dan SDR 17,02\% kemudian masih diikuti oleh Eleusine indica (L) dengan nilai SDR 12,21\% dan 
Clibadium Surinames juga sedikit mendominasi pada arah lereng ini.

Pada kelompok umur 16-20 tahun sudah tidak lagi ditanami tanaman kacangan penutup tanah karena dinilai produksi lateksnya dinilai sudah stabil. Meskipun demikian masih terlihat beberapa tanaman kacangan penutup tanah (LCC) pada beberapa tempat yang berbatasan dengan kebun tanaman karet yang usianya lebih muda maupun tanaman karet yang lebih tua yang usianya sudah diatas 20 tahun dengan diberi penanganan khusus untuk meningkatkan produktivitas hingga umur 25 tahun.

Vegetasi yang tumbuh pada kelompok umur 16-20 tahun biasanya tumbuh secara sporadis, seperti Borreria alata (6,83\%), Mikania micrantha (2,26\%) dan Melastoma malabathricum (6,02\%). Sementara beberapa jenis vegetasi lainnya tumbuh secara bergerombol seperti Paspalum conjugatum Berg (20,78\%), Eleusine indica (L) (14,06\%), Cyperus Kyllingia (6,26\%), Scleria sumantrensis $(7,12 \%)$. Vegetasi yang ditemukan tumbuh tidak bergerombol antara lain Panicum Colonum (2,50\%), Mikania micrantha (2,26\%), Hyptis suavadens (3,66\%) dan Cleome aspera koen (2,59\%).

Paspalum conjugatum Berg dapat ditemukan di ketinggian 0-1800 mdpl pada keadaan tanah yang lembab (Soerjani et al., 1987). Vegetasi ini merupakan gulma tidak penting di perkebunan karet dan pengendalian gulma ini belum perlu dilakukan karena gulma ini bermanfaat sebagai penutup tanah yang mengurangi penguapan dari dalam tanah sehingga kelembaban tanah dapat dijaga. Jenis vegetasi berdaun lebar mendominasi jenis vegetasi yang tumbuh dibawah tegakan tanaman karet, karena kanopi tanaman karet mulai gugur daun sehingga cahaya yang masuk lebih banyak dibandingkan dengan cahaya yang masuk pada tanaman muda. Selain itu pada saat pengamatan dan pengambilan sampel pada tanaman karet usia 16-20 tahun dalam kondisi mengalami fase gugur daun.

Clibadium Surinames mendominasi pada arah lereng utara-selatan sebesar 12,24\% setelah Paspalum conjugatum Berg dan merupakan gulma daun lebar yang statusnya termasuk ke dalam kelompok yang memerlukan pengendalian atau pemberantasan. Gulma ini termasuk ke dalam gulma tahunan yang dapat mencapai tinggi 30-90 $\mathrm{cm}$ dan di beberapa lokasi dapat mencapai 1,5 m. Clibadium Surinames tumbuh di tempat yang tidak ternaungi dan toleran terhadap naungan dan memiliki sistem perakaran yang dalam sehingga memberikan persaingan dalam penyerapan unsur hara. Pengendalian yang dilakukan efektif dengan pendongkelan ketika masih belum terlalu tinggi. (Nasution, 1986) 
Chromolaena odorata tumbuh cukup dominan dengan nilai SDR sebesar 8,93\%, vegetasi yang termasuk ke dalam kelompok vegetasi daun lebar ini tumbuh bergerombol diantara vegetasi rumputan seperti Paspalum conjugatum Berg. Keberadaan vegetasi ini pada umur tanaman 16-20 tahun bukan merupakan gulma penting di perkebunan karet. Di lokasi pengambilan sampel, gulma jenis ini sengaja dibiarkan tumbuh dan akan digunakan sebagai salah satu bahan baku untuk kayu bakar. Selain itu, Chromolaena odorata dapat digunakan sebagai obat mengungari efek samping diabetes dan dapat memperbaiki fungsi hati (Soerjani et al., 1987).

Pada perhitungan koefisien komunitas vegetasi pada kelompok umur 1-5 tahun antara arah lereng barat-timur dan arah lereng utara-selatan menunjukkan nilai 47\% (Tabel 4), pada kelompok umur tanaman taruna 6-10 tahun antara arah lereng barat-timur dan arah lereng utaraselatan menunjukkan nilai $32,15 \%$ (Tabel 5), pada kelompok umur 11-15 tahun antara arah lereng barat-timur dan arah lereng utara-selatan menunjukkan nilai 75,96 \% (Tabel 6), dan pada kelompok umur 16-20 tahun antara arah lereng barattimur dan arah lereng utara-selatan menunjukkan nilai 31,15\% (Tabel 7). Nilai koefisien yang kurang dari $75 \%$ menunjukkan bahwa jenis vegetasi yang tumbuh di kedua lokasi tersebut heterogen atau tidak seragam.

Adanya perbedaan jenis vegetasi yang tumbuh pada masing-masing arah lereng disebabkan oleh beberapa faktor diantaranya suhu, kelembaban dan intensitas cahaya matahari pada setiap arah lereng yang berbeda. Menurut Sulistyono (1995), umur tanaman dan arah lereng berpengaruh terhadap suhu udara serta intensitas cahaya. Suhu serta intensitas cahaya akan semakin kecil dengan arah lereng yang berlawanan dengan datangnya sinar matahari. Keadaan ini disebabkan karena berkurangnya penyerapan (absorbsi) dari udara. Berkurangnya suhu dan intensitas cahaya dapat mengahambat pertumbuhan karena proses fotosintesis terganggu. Semakin bertambah umur karet, maka lebar penutupan tajuk semakin bertambah sehingga mengakibatkan intensitas cahaya semakin kecil. Hal tersebut yang menyebabkan menurunnya komposisi vegetasi yang terdapat di dalam pertanaman karet. Pengaruh intensitas cahaya terhadap pertumbuhan dan perkembangan tanaman sejauh mana berhubungan erat dengan proses fotosintesis. 
Tabel 4. Nilai Summed Dominance Ratio (SDR) jenis vegetasi dan koefisien komunitas (C) pada kelompok umur tanaman muda U1 (1-5 tahun)

\begin{tabular}{llrrr}
\hline \multirow{2}{*}{ No Nama Gulma } & \multicolumn{2}{c}{ SDR (\%) } & \multirow{2}{*}{ Rerata } \\
\cline { 3 - 4 } & \multicolumn{1}{c}{ Barat-Timur } & Utara-Selatan & \\
\cline { 3 - 4 } 1 & Golongan gulma tekian & 15,22 & 9,43 & 12,33 \\
2 & Cyperus Kyllingia & 0,00 & 17,31 & 8,65 \\
3 & Eleusine indica $(L)$ & 12,32 & 0,00 & 6,16 \\
& Ottochloa nodosa & & & \\
3 & Golongan gulma rumputan & 15,35 & 0,00 & 7,68 \\
4 & Mimosa Pudica & 19,81 & 17,44 & 18,63 \\
5 & Clidemia hirta & 0,00 & 7,09 & 3,55 \\
6 & Panicum Repens & 0,00 & 11,18 & 5,59 \\
7 & Scleria sumantrensis & 0,00 & 11,01 & 5,50 \\
& Golongan gulma Daun Lebar & & & \\
8 & Ageratum conyzoides & 9,68 & 6,88 & 8,28 \\
9 & Cleome rutidosprema D.C. & 0,00 & 6,87 & 3,44 \\
10 & Clibadium Surinames & 20,55 & 12,79 & 16,67 \\
11 & Urena Lobata L. & 7,06 & 0,00 & 3,53 \\
\hline & Jumlah & 100,00 & 100,00 & 100,00 \\
\hline & Koefisien komunitas (C) & Barat-Timur : Utara-Selatan & $47 \%$ & \\
\hline
\end{tabular}

Sumber : Data primer diolah, 2016

Tabel 5. Nilai Summed Dominance Ratio (SDR) jenis vegetasi dan koefisien komunitas (C) pada kelompok umur tanaman remaja U2 (6-10 tahun)

\begin{tabular}{|c|c|c|c|c|}
\hline \multirow{2}{*}{ No } & \multirow{2}{*}{ Nama Gulma } & \multicolumn{2}{|c|}{ SDR $(\%)$} & \multirow{2}{*}{ Rerata } \\
\hline & & Barat-Timur & Utara-Selatan & \\
\hline & Golongan gulma tekian & & & \\
\hline 1 & Cyperus Kyllingia & 8,76 & 12,35 & 10,55 \\
\hline \multirow[t]{2}{*}{2} & Eleusine indica $(L)$ & 7,87 & 10,80 & 9,34 \\
\hline & Golongan gulma rumputan & & & \\
\hline 3 & Scleria sumantrensis & 16,83 & 0,00 & 8,42 \\
\hline 4 & Axonopus compresus & 8,62 & 0,00 & 4,31 \\
\hline 5 & Eragrostis uniloides & 6,20 & 0,00 & 3,10 \\
\hline 6 & Panicum repens $L$. & 0,00 & 7,28 & 3,64 \\
\hline \multirow[t]{2}{*}{7} & Paspalum conjugatum Berg & 10,27 & 8,45 & 9,36 \\
\hline & Golongan gulma Daun Lebar & & & \\
\hline 8 & Mucuna bracteata & 22,01 & 20,57 & 21,29 \\
\hline 9 & Ageratum conyzaides & 7,91 & 6,94 & 7,42 \\
\hline 10 & Clibadium Surinames & 11,53 & 12,25 & 11,89 \\
\hline 11 & Phyllantus urinaria L. & 0,00 & 6,67 & 3,34 \\
\hline 12 & Tridax procumbens $L$. & 0,00 & 9,06 & 4,53 \\
\hline \multirow[t]{3}{*}{13} & Urena lobata $L$. & 0,00 & 5,62 & 2,81 \\
\hline & Jumlah & 100,00 & 100,00 & 100,00 \\
\hline & Koefisien komunitas (C) Barat-T & Utara-Selatan & $32,15 \%$ & \\
\hline
\end{tabular}

Sumber : Data primer diolah, 2016 
Tabel 6. Nilai Summed Dominance Ratio (SDR) jenis vegetasi dan koefisien komunitas (C) pada kelompok umur tanaman taruna U3 (11-15 tahun)

\begin{tabular}{|c|c|c|c|c|}
\hline \multirow{2}{*}{ No } & \multirow{2}{*}{ Nama Gulma } & \multicolumn{2}{|c|}{$\operatorname{SDR}(\%)$} & \multirow{2}{*}{ Rerata } \\
\hline & & Barat-Timur & Utara-Selatan & \\
\hline & Golongan gulma tekian & & & \\
\hline 1 & Eleusine indica $(L)$ & 12,73 & 0,00 & 6,37 \\
\hline \multirow[t]{2}{*}{2} & Cyperus Kyllingia & 7,83 & 8,78 & 8,30 \\
\hline & Golongan gulma rumputan & & & \\
\hline 3 & Paspalum conjugatum Berg & 9,57 & 14,57 & 12,07 \\
\hline \multirow[t]{2}{*}{4} & Scleria sumantrensis & 8,88 & 12,83 & 10,85 \\
\hline & Golongan gulma Daun Lebar & & & \\
\hline 5 & Ageratum conyzaides & 8,42 & 6,17 & 7,30 \\
\hline 6 & Clibadium Surinames & 7,51 & 13,38 & 10,44 \\
\hline 7 & Chromolaena odorata & 11,43 & 9,47 & 10,45 \\
\hline 8 & Dryopteris pteroides O.K & 4,34 & 6,78 & 5,56 \\
\hline 9 & Pteris ensiformis Burm & 6,02 & 11,89 & 8,95 \\
\hline \multirow[t]{3}{*}{10} & Calopogonium mucuinoides Desv. & 23,26 & 16,13 & 19,69 \\
\hline & Jumlah & 100,00 & 100,00 & 100,00 \\
\hline & Koefisien komunitas (C) Barat-Tim & Selatan & $75,92 \%$ & \\
\hline
\end{tabular}

Sumber : Data primer diolah, 2016

Tabel 7. Nilai Summed Dominance Ratio (SDR) jenis vegetasi dan koefisien komunitas (C) pada kelompok umur U4 (16-20 tahun)

\begin{tabular}{clrrr}
\hline \multirow{2}{*}{ No } & \multicolumn{1}{c}{ Nama Gulma } & \multicolumn{2}{c}{ SDR (\%) } & \multirow{2}{*}{ Rerata } \\
\cline { 3 - 4 } & Golongan gulma tekian & 15,91 & 12,21 & 14,06 \\
1 & Eleusine indica $(L)$ & 7,19 & 5,33 & 6,26 \\
2 & Cyperus Kyllingia & & & \\
& Golongan gulma rumputan & 24,54 & 17,02 & 20,78 \\
3 & Paspalum conjugatum Berg & 5,36 & 8,88 & 7,12 \\
4 & Scleria sumantrensis & & & \\
& Golongan gulma Daun Lebar & 4,94 & 5,54 & 5,24 \\
5 & Ageratum conyzaides & 3,35 & 12,24 & 7,79 \\
6 & Clibadium Surinames & 9,36 & 8,51 & 8,93 \\
7 & Chromolaena odorata & 5,60 & 6,45 & 6,02 \\
8 & Melastoma malabathricum & 5,55 & 8,10 & 6,83 \\
9 & Borreria alata & 5,17 & 0,00 & 2,59 \\
11 & Cleome aspera koen & 5,71 & 0,00 & 2,85 \\
12 & Gynandropsis gynandrae Briq & 7,31 & 0,00 & 3,66 \\
13 & Hyptis suavadens & 0,00 & 4,53 & 2,26 \\
14 & Mikania micrantha & 0,00 & 6,20 & 3,10 \\
15 & Mollugo pentaphylla & 0,00 & 4,99 & 2,50 \\
16 & Panicum Colonum & 100,00 & 100,00 & 100,00 \\
\hline & Jumlah & $67,87 \%$ & \\
\hline & Koefisien komunitas (C) Barat-Timur : Utara-Selatan & & \\
\hline
\end{tabular}

Sumber : Data primer diolah, 2016 


\section{KESIMPULAN}

1. Keragaman vegetasi gulma yang tumbuh sebanyak 26 jenis gulma dan Gulma dominan yang ditemukan ialah pada kelompok umur muda (1-5 tahun) : Cyperus Kyllingia, Axonopus compressus, Clibadium Surinames kelompok umur remaja (6-10 tahun) : Mucuna bracateata, Scleria sumantrensis, Paspalum conjugatum Berg, kelompok umur taruna (11-15 tahun) : Cyperus Kyllingia, Paspalum conjugatum Berg, Chromolaena odorata., kelompok dewasa (16-20 tahun) : Paspalum conjugatum Berg, Eleusine indica, Chromolaena odorata.

2. Gulma dominan pada arah lereng BaratTimur (BT) ialah Calopogonium mucuinoides Desv., Clibadium Surinames, Paspalum conjugatum Berg, dan jenis gulma yang dominan pada arah lereng Utara-Selatan (US) ialah Calopogonium mucuinoides Desv., Paspalum conjugatum Berg., dan Axonopus Compressus

3. Gulma dominan pada kelompok umur tanaman muda (1-5 tahun) dengan arah lereng Barat-Timur ialah Clibadium Surinames, Axonopus Compressus dan Cyperus Kyllingia, pada arah lereng Utara-Selatan ialah Axonopus Compressus, Eleusine indica (L), Clibadium Surinames. Pada kelompok umur tanaman remaja (6-10 tahun) pada arah lereng barat-timur ialah Scleria sumantrensis, Clibadium Surinames. Pada arah lereng Utara-Selatan yang dominan ialah Cyperus Kyllingia, Clibadium Surinames. Kelompok umur tanaman taruna (11-15 tahun) gulma yang dominan ialah Calopogonium mucuinoides Desv pada arah lereng Barat-Timur maupun arah lereng UtaraSelatan kemudian diikuti Eleusine indica (L), Chromolaena odorata, pada Paspalum conjugatum Berg, Clibadium Surinames. Kelompok umur tanaman dewasa (16-20 tahun) gulma Paspalum conjugatum Berg mendominasi arah lereng Barat-Timur juga Utara-Selatan, kemudian diikuti juga di arah lereng Barat-Timur ada Eleusine indica (L) juga Chromolaena odorata, kemudian pada arah lereng Utara-Selatan juga ada gulma lain Clibadium Surinames, Eleusine indica $(L)$.

\section{DAFTAR PUSTAKA}

Budiarto. 2001. Pengendalian Gulma Kelapa Sawit (ElaeisquineensisJacq.) di Kebun Sekunyir PT Indrotruba Tengah. Kalimantan Tengah. Skripsi Fakultas Pertanian IPB. 67 Hal

Hasanuddin, Erida, G. dan Safmaneli. 2012. Pengaruh Persaingan Gulma Synedrella nodiflora L. pada Berbagai Densitas Terhadap Pertumbuhan Hasil Kedelai. Jurnal Agrista 16(3): 146-152. 
Mangoensoekarjo,S. 1983. Ilmu Gulma dan Cara Pengendaliannya. Latihan Pembekalan Keterampilan Teknik Petugas Lapangan Proyek Terpadu Perkebunan LPP. Yogyakarta.97 Hal

Nasution U. 1984. Gulma dan Pengendalianya di Perkebunan Karet Sumatra dan Aceh. Pusat penelitian \& pengembangan perkebunan tanjung morawa (P4TM). Fakultas Pertanian Universitas Gadjah Mada Yogyakarta. $32 \mathrm{Hal}$

Nasution, U. 1986. Gulma dan pengendaliannya di Perkebunan Karet Sumatera Utara dan Aceh. Pusat Penelitian dan Pengembangan Perkebunan Tanjung Morawa (P4TM): Tanjung Morawa

Oldeman, L.R., 1975. Agroclimatic map of Java \& Madura. Contr. of Centra Res. Inst. for Food Crops 16/76. Bogor.

Rosanti, D. 2011. Jenis- jenis gulma pada perkebunan karet Desa Tanah Abang, Kabupaten Muara Enim, Provinsi Sumatera Selatan. Sainmatika 8: 8- 13.q

Schmidt, F.H. and J.H.A, Ferguson,. 1951. Rainfall Types Based on Wet and Dry Period Ratios for Indonesia and Western New Guinea. Verh. Djawatan Mety. Dan Geofisik, Jakarta 42

Soerjani, M; A.J.G.H, Kostermans dan G, Tjitrosoepomo. 1987. Weed of Rice in Indonesia. Balai Pustaka, Jakarta.

Sulistyono. 1995. Pengaruh Tingggi Tempat Tumbuh Terhadap Produksi Getah Pinus (Pinus merkusii Jungh et. De Vriese) di KPH Probolinggi Perum Perhutani Unit II Jawa Timur. Skripsi Jurusan Manajemen Hutan Fakultas Kehutanan IPB. Bogor
Sutardi. 1981. Analisis Fungsi Produksi Pada Perusda Perkebunan Tlogo Tuntang. Tesis. Semarang: Universitas Dipenogoro. (Online) http://eprints.undip.ac.id/9272/1/199 8MM589.pdf di akses tanggal 4 Desember 2016.

Tjitrosoedirdjo, S.,I. H, Utomo. dan J, Wiroatmodjo. 1984. Pengelolaan Gulma di Perkebunan. PT. Gramedia: Jakarta. 165 Hal 